\author{
Marquette University \\ e-Publications@Marquette
}

College of Nursing Faculty Research and

Publications

Nursing, College of

6-2019

\title{
Functional Exercise Improves Mobility Performance in Older Adults With Type 2 Diabetes: A Randomized Controlled Trial
}

Kimberlee A. Gretebeck

Marquette University, kimberlee.gretebeck@marquette.edu

Caroline S. Blaum

New York University

Tisha Moore

University of Minnesota

Roger Brown

University of Wisconsin - Milwaukee

Andrzej Galecki

University of Michigan - Ann Arbor

See next page for additional authors

Follow this and additional works at: https://epublications.marquette.edu/nursing_fac

Part of the Nursing Commons

\section{Recommended Citation}

Gretebeck, Kimberlee A.; Blaum, Caroline S.; Moore, Tisha; Brown, Roger; Galecki, Andrzej; Strasburg, Debra; Chen, Shu; and Alexander, Neil B., "Functional Exercise Improves Mobility Performance in Older Adults With Type 2 Diabetes: A Randomized Controlled Trial" (2019). College of Nursing Faculty Research and Publications. 842.

https://epublications.marquette.edu/nursing_fac/842 


\section{Authors}

Kimberlee A. Gretebeck, Caroline S. Blaum, Tisha Moore, Roger Brown, Andrzej Galecki, Debra Strasburg, Shu Chen, and Neil B. Alexander 
Marquette University

e-Publications@Marquette

\section{Nursing Faculty Research and Publications/College of Nursing}

This paper is NOT THE PUBLISHED VERSION; but the author's final, peer-reviewed manuscript. The published version may be accessed by following the link in the citation below.

Journal of Physical Activity \& Health, Vol. 16, No. 6 (June 2019) : 461-469. DOI. This article is (C) Human Kinetics and permission has been granted for this version to appear in e-Publications@Marquette. Human Kinetics does not grant permission for this article to be further copied/distributed or hosted elsewhere without express permission from Human Kinetics.

\section{Functional Exercise Improves Mobility Performance in Older Adults with Type 2 Diabetes: A Randomized Controlled Trial}

Kimberlee A. Gretebeck

College of Nursing, Marquette University, Milwaukee, WI

Caroline S. Blaum

Diane \& Arthur Belfer Geriatric Medicine, Division of Geriatric Medicine \& Palliative Care, New York University School of Medicine, New York, NY

Tisha Moore

University of Minnesota Medical Center, Minneapolis, MN

Roger Brown

School of Nursing, University of Wisconsin-Madison, Madison, WI

Andrzej Galecki

Department of Biostatistics, Institute of Gerontology, University of Michigan, Ann Arbor, MI Debra Strasburg

Division of Geriatric Medicine, Mobility Research Center, University of Michigan, Ann Arbor, MI 


\section{Shu Chen}

Biostatistics Department, University of Michigan, Ann Arbor, MI

\section{Neil B. Alexander}

Division of Geriatric and Palliative Medicine, University of Michigan, Ann Arbor, MI Ann Arbor VA Health Care System GRECC

\section{Abstract}

Background: Diabetes-related disability occurs in approximately two-thirds of older adults with diabetes and is associated with loss of independence, increased health care resource utilization, and sedentary lifestyle. The objective of this randomized controlled trial was to determine the effect of a center-based functional circuit exercise training intervention followed by a 10-week customized home-based program in improving mobility function in sedentary older adults with diabetes. Methods: Participants ( $n=111$; mean age 70.5 [7.1] y; mean body mass index 32.7 [5.9] kg/m² were randomized to either a moderate-intensity functional circuit training (FCT) plus 10-week home program to optimize physical activity (FCT-PA) primary intervention or one of 2 comparison groups (FCT plus health education [FCT-HE] or flexibility and toning plus health education [FT-HE]). Results: Compared with FT-HE, FCT-PA improvements in comfortable gait speed of $0.1 \mathrm{~m} / \mathrm{s}(\mathrm{P}<.05)$ and 6 -minute walk of $80 \mathrm{ft}$ were consistent with estimates of clinically meaningful change. At 20 weeks, controlling for $10-$ week outcomes, improvements were found between groups for comfortable gait speed (FCT-PA vs FT-HE and FCT-HE vs FT-HE) and 6-minute walk (FCT-PA vs FCT-HE). Conclusions: Functional exercise training can improve mobility in overweight/obese older adults with diabetes and related comorbidities. Future studies should evaluate intervention sustainability and adaptations for those with more severe mobility impairments.

\section{Keywords}

physical activity; disability; mobility; diabetes

Type 2 diabetes mellitus (T2DM) is a growing epidemic for older adults, affecting 1 in 4 of those aged 65 years and older.[1] Diabetes-related disability occurs in up to two-thirds of older adults with T2DM and is associated with loss of independence, poor quality of life, and increased utilization of acute and long-term health care resources.[ 2] In addition, loss of muscle mass, impaired balance, and decline in muscle strength and endurance are attributed to the aging process.[3] Comorbidities influence mobility limitations, particularly cardiovascular disease and obesity.[4] Nevertheless, even when controlling for these comorbidities, T2DM still accounts for increased lower body disability[ 5] and subclinical mobility impairment.[ 6] These factors, compounded by inactivity, may lead to further mobility impairment in older adults with T2DM.

Lifestyle physical activity interventions hold promise in preventing or improving mobility impairment in older adults with T2DM and comorbidities. [ 7] Results of the Look AHEAD study, a large multicenter trial, indicated that obese older adults in an intensive lifestyle intervention had a $48 \%$ reduction in mobility-related limitations compared with participants in the T2DM support and education group.[ 8] In addition, at 8 years postrandomization, the intervention group reported better physical function and had faster 20- and 400-m walk speeds than the T2DM support and education group.[ 9]

Many older adults with T2DM, including those at high risk for or with subclinical to moderate mobility impairment, can potentially benefit from a structured, moderately intense monitored exercise program for prevention or improvement of mobility disability.[10] Many inactive community-dwelling older 
adults with T2DM and associated comorbidities may find exercise too difficult or not have access to exercise programs in their communities. Thus, a moderate-intensity exercise intervention aimed at improving mobility impairment that can be translated to a home environment and disseminated within a community setting may be ideal for this population. To our knowledge, this is the first study to implement a moderately intensive physical-function-oriented circuit training paradigm that includes lifestyle behavior change in older adults with T2DM. Compared with high-intensity strength or aerobicoriented exercise programs, a moderate-intensity exercise intervention focused on functional tasks may be more acceptable in this population of older adults and may be easier to integrate into a regular physical activity routine.

The purpose of this study was to compare the effects of a 10-week center-based group functional circuit training (FCT) program accompanied by a 10-week individualized home-based lifestyle program with 2 physical activity comparison groups on the primary outcomes of physical function and physical activity in older adults with T2DM. Results from this study can provide a template for structured and sustainable programs to limit mobility disability and to enhance lifestyle physical activity in older adults with T2DM.

\section{Methods}

\section{Study Design}

This study was a randomized controlled trial. Older adults with T2DM were randomized to either a center-based moderate-intensity FCT intervention with lifestyle behavior change to optimize physical activity adoption and maintenance (FCT-PA) or one of 2 comparison groups (FCT with health education [FCT-HE] or low-impact flexibility and toning with health education [FT-HE]). Each group included a 10week center-based exercise training program and a 10-week home-based follow-up. We chose to include active comparison groups because physical activity is a recommended treatment for disease prevention and chronic disease management. Including active comparison groups also minimizes dropout because those who express interest in exercise prefer assignment to an exercise group rather than a health education only or usual care control group. All participants were assessed at baseline, immediately after the 10-week center-based program (10 wk), and after the 10-week follow-up (20 wk). This study was approved by the University of Michigan and Ann Arbor Veterans Affairs Institutional Review Boards, and informed consent was obtained from all study participants.

\section{Participants}

Participants were recruited from Midwestern communities via media advertisement, recruitment flyers posted in primary care settings, and community outreach to senior centers, assisted living complexes, and churches. Participants were included in this study if they were aged 60 years or older, had a T2DM diagnosis, were able to walk across a small room without an assistive device, and did not participate in continuous aerobic exercise of more than 30 minutes, 2 times per week. Participants were excluded from the study if they had symptomatic cardiopulmonary disease, myocardial infarction in the past 6 months, or daily pain that substantially hindered exercise; Folstein Mini Mental State Examination score $<24$ out of 30 ; or report of frequent low or uncontrolled blood glucose.

Potential participants were initially screened by phone, and, if they were eligible, a directed history, medical record review, and physical examination were conducted by a nurse practitioner. Participants 
also had a 2-dimensional echocardiogram to exclude systolic dysfunction or significant valvular disease and a maximal treadmill test to exclude exertion-induced ischemia.

Recruitment resulted in 117 eligible participants enrolled; $41 \%$ of those assessed were eligible and enrolled (Figure 1). Six discontinued after initial enrollment due to disinterest or time commitment. Eligible participants were allocated to a group by a statistician using a computer-based algorithm to minimize differences in key potential confounders of age, gender, and self-reported mobility-relevant function. Using this minimization scheme, an example of adaptive randomization, each participant was allocated to one of the 3 groups based on age (60-75 y vs 75 y and older), gender, and functional mobility disability (total Established Populations for the Epidemiologic Study of the Elderly [EPESE] battery score). The EPESE battery[11] includes mobility-relevant questions, including activities of daily living (such as bathing) and Rosow-Breslau and Nagi items (such as ability to walk upstairs or carrying objects). Minimization is used when the number of stratification cells generated by these factors is large[12] and stipulates that the next participant to enter the trial is assigned to a group that minimizes group imbalance on a particular variable. Initially, the study was planned to evaluate the effectiveness of the moderate-intensity FCT-PA intervention compared with a low-intensity FT-HE control on physical function and physical activity outcomes. During the second year of the study, additional funding was awarded; thus, the FCT-HE control group was added, allowing the evaluation of the effect of the physical activity lifestyle component on the maintenance of physical function outcomes and physical activity during the 10-week follow-up period (FCT-PA vs FCT-HE). At the time the FCT-HE group was added, 42 participants already included in the study were allocated between FCT-PA $(n=21)$ and FT-HE $(n=21)$. For this reason, the 111 participants included in this study were allocated to either FCT-PA, FT$\mathrm{HE}$, or FCT-HE in a final 3:2:1 ratio, resulting in 56 participants in the primary intervention group (FCT$\mathrm{PA})$, and 36 and 19 in the comparison groups (FT-HE and FCT-HE, respectively).

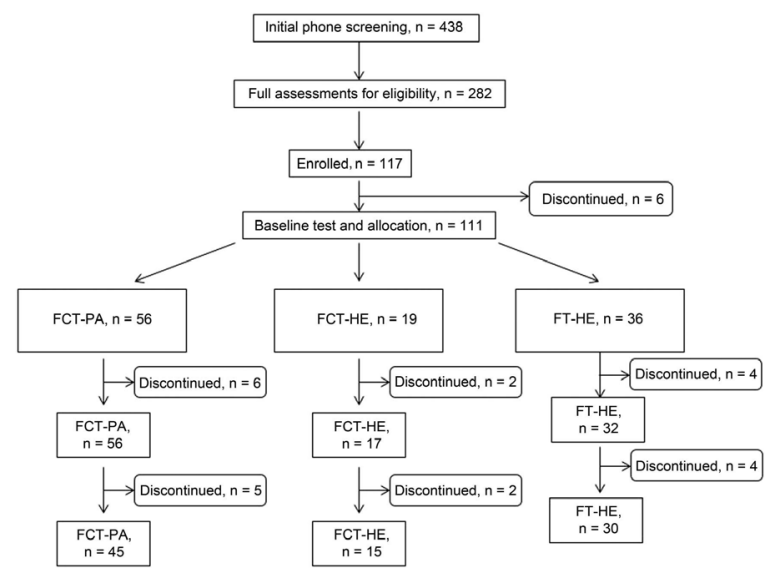

Figure 1 - Consort table. FCT-HE indicates functional circuit training + health education; FCT-PA, functional circuit training + lifestyle physical activity enhancement; FT-HE, flexibility and toning + health education.

\section{Interventions}

Participants exercised in their respective structured exercise group for 50 minutes, 3 days per week, for 10 weeks; either a weekly 30-minute health education class or a lifestyle behavior change class was included. This was followed by a 10-week maintenance period. The intervention components are presented in Table 1. To minimize bias, separate testing and training teams were utilized. Exercise 
classes were led by either a physical therapist or an exercise physiologist. Lifestyle physical activity behavior change and health education classes were led by different nurse practitioners. 
Table 1 Intervention Components

\begin{tabular}{|c|c|c|c|c|}
\hline & & Primary intervention & Comparison groups & \\
\hline Time & Activity & FCT-PA & FT-HE & FCT-HE \\
\hline \multirow[t]{2}{*}{$\begin{array}{l}\text { First } 10 \text { wks: } \\
\text { physical activity } \\
\text { adoption }\end{array}$} & Exercise & $\begin{array}{l}-10 \text {-Min warm-up and cooldown } \\
\text { exercises } 30 \text {-Min moderate-intensity } \\
\text { FCT exercises• Exercise } 2 \text { d outside of } \\
\text { class }\end{array}$ & $\begin{array}{l}\text { - 10-Min warm-up and } \\
\text { cooldown exercises } 30 \text {-Min } \\
\text { low-impact flex and toning } \\
\text { exercises } \text { No exercise outside } \\
\text { of class }\end{array}$ & $\begin{array}{l}-10-\text { Min warm-up and } \\
\text { cooldown exercises } 30 \text {-Min } \\
\text { moderate-intensity FCT } \\
\text { exercises } \bullet \text { No exercise outside } \\
\text { of class }\end{array}$ \\
\hline & $\begin{array}{l}\text { Structured class } \\
\text { for } 30 \min 1 \\
d / w k\end{array}$ & $\begin{array}{l}\text { Lifestyle behavior change class; topics } \\
\text { include overcoming barriers, tracking } \\
\text { physical activity, goal setting, relapse } \\
\text { prevention, eliciting social support, } \\
\text { staying motivated, reinforcement, and } \\
\text { managing time }\end{array}$ & $\begin{array}{l}\text { Diabetes health education } \\
\text { class; topics include reading } \\
\text { labels, proper foot care, } \\
\text { medication adherence, etc }\end{array}$ & $\begin{array}{l}\text { Diabetes health education } \\
\text { class; topics include reading } \\
\text { labels, proper foot care, } \\
\text { medication adherence, etc }\end{array}$ \\
\hline \multirow[t]{3}{*}{$\begin{array}{l}\text { Second } 10 \text { wks: } \\
\text { physical activity } \\
\text { maintenance }\end{array}$} & $\begin{array}{l}\text { Home physical } \\
\text { activity program }\end{array}$ & $\begin{array}{l}\text { - Participants follow the individualized } \\
\text { home program developed by the exercise } \\
\text { trainer } \bullet \text { Instructed to be physically active } \\
\text { for } 30-60 \mathrm{~min} \text { for } 5 \mathrm{~d} / \mathrm{wk}\end{array}$ & $\begin{array}{l}\text { - No home program } \text { No } \\
\text { encouragement to be physically } \\
\text { active }\end{array}$ & $\begin{array}{l}- \text { No home program } \bullet \text { No } \\
\text { encouragement to be physically } \\
\text { active }\end{array}$ \\
\hline & $\begin{array}{l}\text { 20-Min } \\
\text { telephone calls: } \\
\text { weekly } \times 4 \mathrm{wk} ; \\
\text { biweekly } \times 6 \mathrm{wk}\end{array}$ & $\begin{array}{l}\text { Call focuses on identifying barriers to } \\
\text { being physically active, identifying } \\
\text { strategies to overcome barriers, setting } \\
\text { new goals, and discussing changes in } \\
\text { health status }\end{array}$ & $\begin{array}{l}\text { Call focuses on changes in } \\
\text { health status and medications } \\
\text { No discussion related to } \\
\text { physical activity }\end{array}$ & $\begin{array}{l}\text { Call focuses on changes in } \\
\text { health status and medications } \\
\text { No discussion related to } \\
\text { physical activity }\end{array}$ \\
\hline & $\begin{array}{l}\text { Mailings every } 2 \\
\text { wk }\end{array}$ & $\begin{array}{l}\text { Motivational mailings that reinforce } \\
\text { topics discussed in lifestyle behavior } \\
\text { change class to facilitate physical activity } \\
\text { maintenance and prevent relapse }\end{array}$ & $\begin{array}{l}\text { Educational mailings that } \\
\text { reinforce topics discussed in } \\
\text { diabetes health education } \\
\text { class } \bullet \text { No mention of physical } \\
\text { activity in mailings }\end{array}$ & $\begin{array}{l}\text { Educational mailings that } \\
\text { reinforce topics discussed in } \\
\text { diabetes health education } \\
\text { class } \bullet \text { No mention of physical } \\
\text { activity in mailings }\end{array}$ \\
\hline
\end{tabular}

Abbreviations: FCT, functional circuit training; FCT-HE, FCT + health education; FCT-PA, FCT + lifestyle physical activity enhancement; FT-HE, flexibility and toning + health education. 


\section{Functional Circuit Training}

The primary intervention was a group functional circuit exercise program accompanied by a tailored behavior change component to encourage physical activity adoption and maintenance (FCT-PA). The FCT tasks simulated daily functional tasks and sought to improve biomechanical efficiency and skill in these activities while providing an aerobic stimulus. Intermittent activity of large muscle groups incorporated diagonal and rotational motions that are associated with functional activities. Eight functional tasks were embedded in the circuit, including rising from a chair, bending over and picking up objects, stepping over or onto a step, taking large steps, and reaching for and carrying small objects of varying weights. These tasks composed the aerobic portion of the circuit and alternated with stations involving strength training of the large body muscles. Participants initially performed each circuit activity for 60 seconds and completed 2 circuits. Exercise intervals were increased, so that by weeks 6 to 10, participants were performing 30 minutes of continuous activity at a rate of perceived exertion (RPE) of 11 to 13 (light to somewhat hard).[13] Circuit activities increased in intensity and pace as well as duration to achieve the target RPE. Heart rate was monitored with the recognition that in some participants, beta blocker medications might blunt the heart rate response to exercise. Each class began and ended with a 10-minute warm-up and 10-minute cooldown that included mild stretching and flexibility exercises.

\section{Physical Activity Enhancement}

To facilitate behavior change and adoption of long-term physical activity behavior, FCT-PA participants were instructed to participate in physical activity they enjoy for 30 minutes 1 day per week in addition to the structured group exercise class at an RPE of 11 to 13 during weeks 2 to 4 of the intervention and to increase this activity to 2 days outside of class during the last 5 weeks, building up to the recommended 150 minutes of physical activity per week.[14] In addition to the 10-week FCT group exercise class, FCT-PA participants also attended a weekly 30-minute group lifestyle physical activity behavior change session led by a nurse practitioner. The lifestyle physical activity behavior change classes focused on skill building of self-regulation strategies (eg, setting realistic goals, self-monitoring, relapse prevention) and increasing self-efficacy for maintenance of physical activity once the 10-week structured group exercise class was completed. The curriculum for the behavior change sessions was developed by the investigators based on social cognitive theory. Prior to the intervention, the nurse practitioners participated in training that included demonstrating competence in delivering the theorybased behavior change content accurately and effectively leading a group discussion. In consultation with the FCT group trainers, tailored lifestyle home exercise programs were developed and then adjusted based on each participant's progress during the 10 -week follow-up period. The individualized home program included exercises from the FCT as well as lifestyle activities that each participant preferred, such as walking, doing yardwork, and so on. During the 10-week follow-up period, the FCTPA group received weekly 20-minute telephone calls for the first month and biweekly calls for the remaining 6 weeks from the same nurse practitioner that conducted the lifestyle physical activity behavior change class. The primary focus of the phone calls was to encourage participants to follow their individualized home program, assess physical activity, and use the self-regulatory skills learned during the lifestyle behavior change classes to prevent relapse and to establish new goals. Participants also received motivational mailings every 2 weeks aimed at physical activity maintenance. During the 
10-week home program, participants were instructed to engage in 30 to 60 minutes of physical activity 5 days per week.

\section{Flexibility and Toning}

Flexibility and toning group activities were performed primarily in a seated position, using relatively low-resistance thera-tubing and light hand weights. Participants performed up to 10 repetitions of 8 to 10 separate exercises that used all the major muscle groups. As the training progressed, participants first increased repetitions and then increased resistance. The flexibility portion of the class also focused on the major muscle groups; stretches were held to the point of mild discomfort for 10 to 30 seconds and repeated 3 to 4 times. As the goal was not to provide an aerobic stimulus, participants were monitored to ensure that their self-reported RPE was between 6 and 10 (very easy). Participants were not encouraged to exercise outside of their exercise class.

\section{Health Education}

During the first 10 weeks, the 2 comparison groups (FCT-HE and FT-HE) participated in weekly 30 minute diabetes health education classes facilitated by a nurse practitioner. The classes were designed to increase participants' knowledge of T2DM-related topics but not to increase their physical activity levels. The American Diabetes Association curriculum was used and included a variety of topics related to T2DM self-management (eg, reading food labels, foot care, annual health screenings). No physical activity content was included or discussed. As an attention control to the primary intervention, the FCT-HE and FT-HE comparison groups received telephone calls during the 10-week follow-up period from the same nurse practitioner, that facilitated the T2DM health education class. The calls focused on monitoring changes in health or medications. Activity encouragement and behavioral change/support were purposefully not provided. Participants also received T2DM health education mailings every 2 weeks. These activities occurred at the same time points as those for the FCT-PA primary intervention group, and the amount of time spent between all 3 groups was equivalent.

\section{Outcome Measures}

Measures were evaluated at baseline, after the 10-week group exercise class, and following the 10week home maintenance program (at $20 \mathrm{wk}$ ). The primary outcome measures for physical function (comfortable gait speed [CGS] and 6-min walk) and physical activity are well-established, are frequently used in intervention studies with older adults with comorbidities, and have established good to excellent reliability and validity.[15]-[17] For CGS (in meters per second), participants were instructed to walk $10 \mathrm{~m}$ at a comfortable speed. Time was measured for the intermediate $6 \mathrm{~m}$ of the 10-m course, allowing for acceleration and deceleration. For 6-minute walk distance (feet walked in $6 \mathrm{~min}$ ), participants were instructed to cover as much ground as they could comfortably walk on a hallway course for 6 minutes. The Community Healthy Activities Model Program for Seniors (CHAMPS) questionnaire was used to measure total physical activity; it is specifically designed to evaluate lifestyle intervention-induced changes in a broad range of physical activities.[17],[18] We used the scoring and algorithms described by Stewart et al[17] to calculate total caloric energy expenditure per week. More specifically, each low-, moderate-, and vigorous-intensity physical activity item (a total of 28 items) was assigned a specific metabolic equivalent value based on Stewart et al,[17] then multiplied by the estimated duration of each activity (in hours per week) and summed across all pertinent activities. The specific metabolic equivalent value for each of the 28 activities can be found in Stewart et al.[17] 
Secondary metabolic outcome measures included body mass index (BMI), fasting glucose, insulin, lipids, and $\mathrm{HbA}_{1 \mathrm{c}}$.

\section{Data Analysis}

Power calculations were performed for the outcome variable CGS. From our preliminary study, the difference between CGS means was 0.08 , SD was 0.13 , and effect size was 0.61 . At $80 \%$ power to detect an effect size of 0.61 with $\alpha=.05,43$ participants were needed per group.

\section{Main Hypothesis (Baseline to 20 Wk) Analysis}

A regression linear/mixed-effects model with intent to treat analysis was conducted to assess the between-group intervention effects on physical function (CGS and 6-min walk) and total physical activity. We examined whether there was a group by time effect between baseline and 20 weeks, with time treated as a categorical variable. Covariates included age, gender, EPESE function, BMI, and the baseline outcome variable. These analyses yielded a delta estimate (and the SE of the estimate), which represented the difference between the groups at 20 weeks.

\section{Secondary 10- and 20-Week Analyses}

Given that there were different 10-week center-based exercise groups and follow-up activities, a secondary analysis was performed to determine between-group differences at 10 weeks (adjusting for baseline) and at 20 weeks (adjusting for 10-week outcomes). A model similar to that described above was used, with time treated as a categorical variable and controlling for age, gender, EPESE function, BMI, and outcome variables.

\section{Results}

The intervention and comparison groups were similar in baseline characteristics (Table 2). For the total sample of participants, the mean age was 70.5 (7.1) years, $77.1 \%$ of participants were white, $22.9 \%$ were African American, and 61\% were female. Many participants were obese or overweight (mean BMI $32.7[5.94] \mathrm{kg} / \mathrm{m}^{2}$ ), had more than 2 comorbidities, and were in good diabetes control (mean $\mathrm{HbA}_{1 \mathrm{c}}$ 6.7-7.1). There were few significant differences in baseline characteristics between the groups with the exception of BMI and arthritis. The FCT-HE comparison group had a lower BMI (30 [ 5] kg/m²) than the FCT-PA and FT-HE groups (33 [6] and 34 [ 7] kg/m², respectively), and the FCT-PA intervention group had fewer participants with arthritis (23\%) than the 2 comparison groups (47\% and $53 \%$ ). No significant changes were noted over time for the secondary outcome measures of BMI, fasting glucose, insulin, lipids, and $\mathrm{HbA}_{1 \mathrm{c}}$ after adjusting for baseline values. Results are focused on CGS, 6-minute walk, and total physical activity. 
Table 2 Baseline Participant Characteristics by Group

\begin{tabular}{|c|c|c|c|c|c|}
\hline & & Primary intervention & Comparison groups & & \\
\hline Participant characteristic & n & $\begin{array}{l}\text { FCT-PA ( } n=56), n(\%) \\
\text { or mean (SD) }\end{array}$ & $\begin{array}{l}\text { FT-HE }(n=36), n(\%) \text { or mean } \\
\text { (SD) }\end{array}$ & $\begin{array}{l}\text { FCT-HE }(n=19), n(\%) \text { or mean } \\
(S D)\end{array}$ & $P$ value \\
\hline Age, $y$ & 111 & $70(6)$ & $71(8)$ & $71(9)$ & .81 \\
\hline Gender, female & 111 & $35(64 \%)$ & $20(56 \%)$ & $13(68 \%)$ & .63 \\
\hline Race, white & 108 & $42(75 \%)$ & $30(83 \%)$ & $11(58 \%)$ & .13 \\
\hline \multicolumn{6}{|l|}{ Education } \\
\hline$\leq 12 \mathrm{y}$ & 17 & $11(20 \%)$ & $3(9 \%)$ & $3(16 \%)$ & .36 \\
\hline Some college or more & 90 & $45(80 \%)$ & $30(91 \%)$ & $15(79 \%)$ & \\
\hline Body mass index & 111 & $33(6)$ & $34(7)$ & $30(5)$ & $.02 *$ \\
\hline Total EPESE & 111 & $3.0(2.9)$ & $2.6(2.2)$ & $2.7(2.2)$ & .35 \\
\hline \multicolumn{6}{|l|}{ Prevalent diseases } \\
\hline Hypertension & 111 & $45(80 \%)$ & $31(86 \%)$ & $16(84 \%)$ & .77 \\
\hline Coronary heart disease & 111 & $8(14 \%)$ & $4(11 \%)$ & $1(5 \%)$ & .59 \\
\hline Arthritis & 111 & $13(23 \%)$ & $17(47 \%)$ & $10(53 \%)$ & $.02 *$ \\
\hline$\geq 2$ chronic diseases & 111 & $30(54 \%)$ & $20(56 \%)$ & $12(63 \%)$ & .77 \\
\hline $\mathrm{VO}_{2}$ peak $\left(\mathrm{mL} \cdot \mathrm{kg}^{-1} \cdot \mathrm{min}^{-1}\right)$ & 109 & $17(5)$ & $17(4)$ & $16(6)$ & .90 \\
\hline Fasting glucose & 106 & $131(37)$ & $135(52)$ & $124(45)$ & .39 \\
\hline High density lipoprotein cholesterol & 106 & $52(17)$ & $48(12)$ & $53(14)$ & .22 \\
\hline Low density lipoprotein cholesterol & 106 & $84(30)$ & $85(34)$ & $92(28)$ & .46 \\
\hline $\mathrm{HbA}_{1 \mathrm{c}}$ & 104 & $7.0(1.1)$ & $7.1(1.4)$ & $6.7(1.5)$ & .34 \\
\hline \multicolumn{6}{|l|}{ Primary outcomes } \\
\hline 6-Min walk, ft & 110 & $1337(246)$ & $1293(236)$ & $1318(307)$ & .61 \\
\hline Comfortable gait speed, $\mathrm{m} / \mathrm{s}$ & 110 & $1.2(0.2)$ & $1.2(0.2)$ & $1.2(0.2)$ & .99 \\
\hline Total physical activity, kcal/wk & 107 & $2440(2083)$ & 2651 (2089) & $2069(1967)$ & .35 \\
\hline
\end{tabular}

Abbreviations: EPESE, Established Populations for the Epidemiologic Study of the Elderly; FCT-HE, functional circuit training + health education; FCT-PA, functional circuit training + lifestyle physical activity enhancement; FT-HE, flexibility and toning + health education. Note: $P$ values from 2 independent sample $t$ tests except for total physical activity, which are Wilcoxon-Mann-Whitney test. $* P<.05$. 
Of the 111 participants enrolled in the study, 6 discontinued after the initial enrollment due to disinterest or time commitment. By the end of the 20-week intervention, 21 participants had discontinued participation for reasons unrelated to the exercise classes, including cancer diagnosis requiring treatment $(n=1, F C T-P A)$, respiratory infections, including pneumonia ( $n=3, F C T-P A ; n=2$, FT-HE; $n=1, F C T-H E)$, back pain ( $n=1, F T-H E)$, knee or hip pain ( $n=3, F C T-P A ; n=1, F C T-H E)$, and surgery $(n=1, F T-H E)$. The remaining 8 participants did not disclose a reason for dropping out. The 20week attrition rate was $19 \%$ overall and was similar across the 3 groups ( $20 \%$ for FCT-PA, $21 \%$ for FCT$\mathrm{HE}$, and $17 \%$ for FT-HE). Attendance rate for the exercise classes during the first 10 weeks was $76 \%$, with no significant difference between groups. Regardless of group assignment, participants improved in each outcome as a result of their respective 10-week center-based exercise group (Table 3). 
Table 3 Study Variables' Unadjusted Means (SDs) at 3 Time Points for Intervention and Comparison Groups

\begin{tabular}{|c|c|c|c|c|c|c|c|c|c|}
\hline & $\begin{array}{l}\text { Primary } \\
\text { intervention }\end{array}$ & & & \begin{tabular}{|l|}
$\begin{array}{l}\text { Comparison } \\
\text { groups }\end{array}$ \\
\end{tabular} & & & & & \\
\hline & FCT-PA & & & FT-HE & & & FCT-HE & & \\
\hline Study variable & Baseline & $10 w k$ & $20 w k$ & Baseline & $10 \mathrm{wk}$ & $20 w k$ & Baseline & $10 \mathrm{wk}$ & $20 w k$ \\
\hline \multicolumn{10}{|l|}{$\begin{array}{l}\text { Comfortable gait } \\
\text { speed, } \mathrm{m} / \mathrm{s}\end{array}$} \\
\hline NM (SD) & $551.19(0.22)$ & $\begin{array}{l}501.23 \\
(0.23)\end{array}$ & $\begin{array}{l}451.29 \\
(0.21)\end{array}$ & $361.19(0.20)$ & $\begin{array}{l}321.21 \\
(0.19)\end{array}$ & $\begin{array}{l}301.18 \\
(0.22)\end{array}$ & $\begin{array}{l}191.19 \\
(0.22)\end{array}$ & $\begin{array}{l}171.26 \\
(0.23)\end{array}$ & $\begin{array}{l}151.26 \\
(0.25)\end{array}$ \\
\hline \multicolumn{10}{|l|}{ 6-min walk, ft } \\
\hline NM (SD) & $\begin{array}{l}561337.29 \\
(245.79)\end{array}$ & $\begin{array}{l}491437.71 \\
(276.28)\end{array}$ & $\begin{array}{l}451505.27 \\
(271.30)\end{array}$ & $\begin{array}{l}361293.25 \\
(236.17)\end{array}$ & $\begin{array}{l}321357.69 \\
(307.92)\end{array}$ & $\begin{array}{l}291369.10 \\
(343.07)\end{array}$ & $\begin{array}{l}181318.00 \\
(306.65)\end{array}$ & $\begin{array}{l}171381.77 \\
(330.46)\end{array}$ & $\begin{array}{l}151407.67 \\
(398.47)\end{array}$ \\
\hline \multicolumn{10}{|l|}{ Total PA, kcal/wk } \\
\hline $\mathrm{NM}(\mathrm{SD})$ & $\begin{array}{l}562440.28 \\
(2083.20)\end{array}$ & $\begin{array}{l}463675.92 \\
(3033.82)\end{array}$ & $\begin{array}{l}363391.52 \\
(3140.95)\end{array}$ & $\begin{array}{l}332651.15 \\
(2088.92)\end{array}$ & $\begin{array}{l}324300.12 \\
(3567.78)\end{array}$ & $\begin{array}{l}263142.32 \\
(2561.68)\end{array}$ & $\begin{array}{l}182069.21 \\
(1967.13)\end{array}$ & $\begin{array}{l}162122.22 \\
(1705.63)\end{array}$ & $\begin{array}{l}141877.59 \\
(1816.17)\end{array}$ \\
\hline
\end{tabular}

Abbreviations: FCT-HE, functional circuit training + health education; FCT-PA, functional circuit training + physical activity enhancement; FT-

$\mathrm{HE}$, flexibility and toning + health education. 
Main Hypothesis (Baseline to 20-Wk) Analysis

The FCT-PA primary intervention group showed significantly greater improvement in CGS than the FTHE group by $0.1 \mathrm{~m} / \mathrm{s}(P<.05$, see Table 4$)$. FCT-HE showed a similar trend in CGS improvement over FT$\mathrm{HE}$ although did not reach statistical significance. For the 6-minute walk, there was a trend in improvement of $80 \mathrm{ft}$ for FCT-PA versus FT-HE and $93 \mathrm{ft}$ for FCT-HE versus FT-HE although not statistically significant. For total physical activity, there was minimal improvement in the FCT-PA group that was not significantly different from FT-HE. 
Table 4 Differences in Change Between Groups in Outcome Variables

\begin{tabular}{|c|c|c|c|c|c|c|c|c|c|c|c|c|c|}
\hline & & $\begin{array}{l}\text { Comfortable } \\
\text { gait speed, } \\
\mathrm{m} / \mathrm{s}\end{array}$ & & & & $\begin{array}{l}\text { 6-Min walk } \\
\text { distance, } \mathrm{ft}\end{array}$ & & & & $\begin{array}{l}\text { Total physical } \\
\text { activity, } \\
\text { kcal/wk }\end{array}$ & & & \\
\hline & Comparison & $\begin{array}{l}\text { Delta } \\
\text { estimate }\end{array}$ & SE & $\mathbf{t}$ & $P$ value & $\begin{array}{l}\text { Delta } \\
\text { estimate }\end{array}$ & SE & $\mathbf{t}$ & $P$ value & $\begin{array}{l}\text { Delta } \\
\text { estimate }\end{array}$ & SE & $t$ & $P$ value \\
\hline \multirow{3}{*}{$\begin{array}{l}20 \text { wk vs } \\
\text { baseline }\end{array}$} & FCT-PA vs FT-HE & .10 & .05 & 2.2 & $.03 *$ & 80.0 & 46.0 & 1.74 & .09 & 260.7 & 424.7 & .61 & .50 \\
\hline & FCT-HE vs FT-HE & .12 & .06 & 1.9 & .06 & 93.2 & 59.0 & 1.58 & .12 & -844.70 & 543.0 & $\begin{array}{l}- \\
1.56\end{array}$ & .13 \\
\hline & FCT-HE vs FCT-PA & .01 & .06 & .20 & .84 & 13.2 & 55.8 & .24 & .81 & -1105.5 & 523.0 & $\begin{array}{l}- \\
2.11\end{array}$ & $.04^{*}$ \\
\hline \multirow{3}{*}{$\begin{array}{l}10 \text { wk vs } \\
\text { baseline }\end{array}$} & FCT-PA vs FT-HE & -.03 & .04 & -82 & .41 & 18.3 & 47.8 & .38 & .70 & 612.2 & 495.3 & 1.24 & .22 \\
\hline & FCT-HE vs FT-HE & -.004 & .05 & -.07 & .94 & 37.3 & 60.9 & .61 & .54 & -499.1 & 606.2 & -.82 & .41 \\
\hline & FCT-HE vs FCT-PA & .28 & .05 & .61 & .55 & 19.0 & 57.60 & .33 & .07 & -1111.3 & 565.1 & $\begin{array}{l}- \\
1.97\end{array}$ & .05 \\
\hline \multirow{3}{*}{$\begin{array}{l}20 \mathrm{wk} v \mathrm{~s} \\
10 \mathrm{wk}\end{array}$} & FCT-PA vs FT-HE & .14 & .04 & 3.7 & $.001 *$ & 61.7 & 29.8 & 2.07 & $.04^{*}$ & -351.5 & 462.4 & -.76 & .45 \\
\hline & FCT-HE vs FT-HE & .12 & .05 & 2.5 & $.02 *$ & 55.9 & 38.6 & 1.45 & .15 & -345.7 & 573.7 & -.60 & .55 \\
\hline & FCT-HE vs FCT-PA & -.02 & .05 & -.36 & .72 & -5.84 & 36.7 & -.16 & .87 & 5.77 & 537.1 & .01 & .99 \\
\hline
\end{tabular}

Abbreviations: FCT-HE, functional circuit training + health education; FCT-PA, functional circuit training + physical activity enhancement; FT$\mathrm{HE}$, flexibility and toning + health education. ${ }^{*} P<.05$. 
Secondary 10- and 20-Week Analyses

Group comparisons of differences in outcome variables from baseline to 10 weeks (immediately following the 10-wk center-based exercise classes) and 10 to 20 weeks (following the 10-wk maintenance period) are presented in Table 4. The improvement in CGS in FCT-PA versus FT-HE was not significant at 10 weeks adjusting for baseline and reached $0.135 \mathrm{~m} / \mathrm{s}$ at 20 weeks adjusting for 10 weeks $(P<.001)$. Compared with FT-HE, FCT-HE showed no significant improvement at 10 weeks adjusting for baseline CGS but reached an improvement of $0.12 \mathrm{~m} / \mathrm{s}$ at 20 weeks adjusting for 10 weeks $(P<.05)$. For the 6-minute walk, the FCT-PA and FCT-HE groups did not significantly differ at 10 weeks adjusting for the baseline 6-minute walk outcome, but FCT-PA significantly improved (by $61.7 \mathrm{ft}$ ) at 20 weeks adjusting for the 10 -week 6 -minute walk outcome $(P<.05)$. For total physical activity, none of the group comparisons significantly differed at 10 weeks adjusting for baseline or at 20 weeks adjusting for 10-week total physical activity.

\section{Discussion}

Older adults with T2DM and comorbidities improved their mobility function (CGS and 6-min walk) following a 10-week moderately intense lifestyle physical-function-oriented group circuit training program and maintained those improvements after transitioning to a 10-week individualized homebased telephonic-supported physical activity program.

The FCT-PA intervention improvements in CGS of $0.1 \mathrm{~m} / \mathrm{s}$ and 6 -minute walk of $80 \mathrm{ft}(24.38 \mathrm{~m})$ are consistent with estimates of substantial $(0.08-0.14 \mathrm{~m} / \mathrm{s})[16]$ and small $(20 \mathrm{~m})$ clinically meaningful changes, respectively.[16] The mean CGS of $1.2 \mathrm{~m} / \mathrm{s}$ in this study is associated with better functional outcomes and increased life expectancy.[19] A decrease in CGS of $0.1 \mathrm{~m} / \mathrm{s}$ in older adults has been associated with a $10 \%$ decrease in the ability to perform daily living activities.[20] In addition, Perera et al[16] suggested that $0.05 \mathrm{~m} / \mathrm{s}$ represents a small meaningful change, whereas $0.1 \mathrm{~m} / \mathrm{s}$ is a substantial meaningful change in CGS. The CGS is a consistent risk factor for disability, cognitive impairment, institutionalization, falls, and mortality,[19] and thus has been suggested as an assessment tool for clinicians.[21] Perera et al[16] also suggested that a 20-m improvement in 6-minute walk represents a small meaningful change, with a substantial meaningful change at $50 \mathrm{~m}$ for community-dwelling older adults and subacute stroke survivors.

For total physical activity, the mean estimates of baseline and change, as well as relatively large SE of the estimates, are consistent with previous studies, particularly with overweight $(\mathrm{BMI}>27$ ) participants. [17] Compared with FT-HE controls, the FCT-PA intervention group improved in total physical activity following the 10-week center-based FCT exercise class and at 20 weeks (controlling for baseline), but the tendency was not statistically significant. Interestingly, at 20 weeks, controlling for 10-week outcomes, the differences between groups for total CHAMPS decreased and were not significant, while significant improvements were found between groups for CGS (FCT-PA vs FT-HE and FCT-HE vs FT-HE) and 6-minute walk (FCT-PA vs FCT-HE). Given the improvement in mobility outcomes, the reasons for the lack of a significant intervention effect on total physical activity in this study are not completely clear but may include the high variability in CHAMPS physical activity data, a relatively weak relationship between mobility and self-reported physical activity in CHAMPS $(r=.22)$,[17] and the use of active controls. In addition, the CHAMPS questionnaire is a self-report measure of physical activity; thus, participants may have overreported or underreported their physical activity. In future 
studies, it may be beneficial to collect CHAMPS physical activity data via an interview format for older adults with several comorbidities and T2DM-related problems, such as visual impairment. Future studies should also include an objective physical activity measure, such as accelerometry, which seems to correlate better than CHAMPS with physical activity determined by gold standard doubly labeled water studies.[18] An objective measure of physical activity may have been particularly important in the sedentary participants included in this study that tended to participate mainly in low-intensity activities.[22]

Few exercise programs focus on older adults with T2DM and comorbidities. The FCT model helped participants to maintain cardiovascular intensity for longer durations. The functional task-specific training was designed for participants to integrate training activities into their daily routine and to enhance physical activity and mobility. Standard resistance training circuits proposed for older adults are typically more physically challenging (eg, 60\%-85\% 1-repetition maximum) and focus on improving strength, cardiac, and body composition parameters. [23] Mobility-related outcomes (such as CGS and 6-min walk) are more likely to improve by the nature of the FCT weight-bearing tasks and interstation walking requirements. The finding of significant improvements in CGS and 6-minute walk for the primary intervention group (when compared with the FT-HE control group) reinforces the mobilityrelated physical function benefits of participating in a moderately intense group-based lifestyle circuit training program that transitions to an individualized home-based program. Balance- and walkingfocused training programs may be appropriate for older adults with T2DM-related peripheral neuropathy.[24] Other community-based exercise programs (such as tai chi) have not yet been proven in controlled trials to improve mobility in older adults with T2DM.[25]

The FCT effect may be related to benefits of group interaction, which also permits oversight for a greater number of participants than standard physical therapy rehabilitation models. The present program and outcomes are similar to those in task-specific group circuit training in patients with neurological disorders[26],[27] and, thus, may be applied to other groups of older adults with comorbidities. The differential FCT intervention effect (FCT-PA and FCT-HE vs FT-HE) was strongest after the home maintenance period (at $20 \mathrm{wk}$ ), suggesting that the center-based program successfully transitioned into the home program and thereby enhanced the potential sustainability of this training model. Compared with less frequent traditional clinic face-to-face encounters, frequent biweekly telephone follow-up provides focused and individualized real-time problem-solving for physical activity maintenance. Other 12-week standard circuit resistance/aerobic training programs in adults with T2DM have demonstrate a continued positive effect on gait parameters up to 8 weeks posttraining.[28] Resistance training gains can be maintained up to 6 months with a home-resistance training program in older adults with T2DM.[29]

Unique in the present design is the use of a center-based intervention (FCT) versus an active exercise control (FT), as well as a customized lifestyle physical activity enhancement versus attention-control health education. The use of an active exercise control not only decreases the primary intervention effect size but also reflects the reality that older adults with T2DM may exercise if given the opportunity. Questions remain regarding the optimum type, duration, and intensity of this exercise, and which older adults with T2DM to target. 
This study has limitations, which should be considered. The sample size was smaller than desired due to time limitations to conduct the study, difficulty in recruiting participants, and dropouts. A larger sample size may have increased the power of some of the calculations. In addition, there was no correction for the limited amount of statistical comparisons. Most participants were white, fairly well educated, and lived in urban areas in the Midwest, limiting the generalizability of findings. The use of an active exercise control may have decreased the primary intervention effect size, although allocating all participants to an exercise group likely prevented the higher dropout rates that are seen in many physical activity studies in older adults with T2DM. The present cohort was similar to other older adult exercise cohorts-generally sedentary, overweight, or obese, and with a history of T2DM, hypertension, arthritis, and other chronic diseases.[30] Yet, based on CGS, the cohort in this study may not have been as impaired as those in large epidemiologic samples of older adults with T2DM, which include substantial cardiovascular, vision, and neuropathy disease burden. Future studies should consider recruitment of more impaired older adults with T2DM with a CGS of $1.0 \mathrm{~m} / \mathrm{s}$ or less, given an estimate of dysmobility at $0.6 \mathrm{~m} / \mathrm{s}$.[31]

In conclusion, a center-based group FCT exercise program that includes lifestyle behavior change and an individualized home exercise program with telephonic support in older adults with T2DM can improve physical function outcomes in older adults with T2DM and its associated comorbidities. Future studies should evaluate the long-term sustainability of this model and adapt the physical-functionoriented circuit for older adults with more severe impairments.[32]

Gretebeck is with the College of Nursing, Marquette University, Milwaukee, WI. Blaum is with Diane \& Arthur Belfer Geriatric Medicine, Division of Geriatric Medicine \& Palliative Care, New York University School of Medicine, New York, NY. Moore is with the University of Minnesota Medical Center, Minneapolis, MN. Brown is with the School of Nursing, University of Wisconsin-Madison, Madison, WI. Galecki is with the Department of Biostatistics, Institute of Gerontology, University of Michigan, Ann Arbor, MI. Strasburg is with the Division of Geriatric Medicine, Mobility Research Center, University of Michigan, Ann Arbor, MI. Chen is with Biostatistics Department, University of Michigan, Ann Arbor, MI. Alexander is with the Division of Geriatric and Palliative Medicine, University of Michigan, Ann Arbor, $\mathrm{MI}$, and the Ann Arbor VA Health Care System GRECC.

\section{Acknowledgments}

The authors thank the members of our research team at the University of Michigan-Wendy Champoux, Nancy Ambrose Gallagher, Brad Grincewicz, Martina Nabozny, Linda Nyquist, Eric Pear, Diane Scarpace, Debra Strasburg, and Elisa Torres-for their assistance with participant screening, data collection, and exercise training. This work was supported by the Office of Research and Development of the Department of Veterans Affairs (E0-9606) and the American Diabetes Association (1-06-JF-20). The authors also acknowledge the support of the National Institute of Health Claude Pepper Center (AG024824), Michigan Institute for Clinical \& Health Research (UL1TR000433), the Michigan Diabetes Research and Training Center (DK020572) and K24 (AG109675), and the Dorothy and Herman Miller Fund for Mobility Research in Older Adults. This study is registered at www.clinicaltrials.gov (No. NCT00344240). 


\section{References}

1. Centers for Disease Control and Prevention. National Diabetes Statistics Report: Estimates of Diabetes and Its Burden in the United States, 2014. Atlanta, GA: Department of Health and Human Services; 2014.

2. Blaum CS, Ofstedal MB, Langa KM, Wray LA. Functional status and health outcomes in older Americans with diabetes mellitus. J Am Geriatr Soc. 2003;51:745-753. PubMed ID: 12757559 doi:10.1046/j.1365-2389.2003.51256.x

3. Sakuma K, Yamaguchi A. Sarcopenia and age-related endocrine function. Int J Endocrinol.2012;2012:1-10. PubMed ID: 22690213 doi:10.1155/2012/127362

4. Kalyani RR, Saudek CD, Brancati FL, Selvin E. Association of diabetes, comorbidities, and A1C with functional disability in older adults: results from the National Health and Nutrition Examination Survey (NHANES), 1999-2006. Diabetes Care. 2010;33:1055-1060. PubMed ID: 20185736 doi:10.2337/dc09-1597

5. Al Snih S, Fisher MN, Raji MA, Markides KS, Ostir GV, Goodwin JS. Diabetes mellitus and incidence of lower body disability among older Mexican Americans. J Gerontol A Biol Sci Med Sci. 2005;60:1152-1156. PubMed ID: 16183955 doi:10.1093/gerona/60.9.1152

6. de Rekeneire N, Rooks RN, Simonsick EM, et al. Racial differences in glycemic control in a wellfunctioning older diabetic population. Findings from the Health, Aging and Body Composition Study. Diabetes Care. 2003;26:1986-1992. PubMed ID: 12832300 doi:10.2337/diacare.26.7.1986

7. Rejeski WJ, Bray GA, Chen SH, et al. Aging and physical function in type 2 diabetes: 8 years of an intensive lifestyle intervention. J Gerontol A Biol Sci Med Sci. 2015;70:345-353. PubMed ID: 24986062 doi:10.1093/gerona/glu083

8. Rejeski WJ, Ip EH, Bertoni AG, et al; Look AHEAD Research Group. Lifestyle change and mobility in obese adults with type 2 diabetes. N Engl J Med. 2012;366:1209-1217. PubMed ID: 22455415 doi:10.1056/NEJMoa1110294

9. Houston DK, Leng X, Bray GA, et al; Action for Health in Diabetes (Look AHEAD) Movement and Memory Ancillary Study Research Group. A long-term intensive lifestyle intervention and physical function: the look AHEAD movement and memory study. Obesity. 2015;23:77-84. PubMed ID: 25452229 doi:10.1002/oby.20944

10. Fiatarone Singh MA. Exercise in the oldest old: some new insights and unanswered questions. $J$ Am Geriatr Soc. 2002;50:2089-2091. PubMed ID: 12473025 doi:10.1046/j.15325415.2002.50626.x

11. Smith LA, Branch LG, Scherr PA, et al. Short-term variability of measures of physical function in older people. J Am Geriatr Soc. 1990;38:993-998. doi:10.1111/j.1532-5415.1990.tb04422.x

12. Taves DR. Minimization: a new method of assigning patients to treatment and control groups. Clin Pharmacol Ther. 1974;15:443-453. doi:10.1002/cpt1974155443

13. Lamb KL, Eston RG, Corns D. Reliability of ratings of perceived exertion during progressive treadmill exercise. Br J Sports Med. 1999;33:336-339. PubMed ID: 10522637 doi:10.1136/bjsm.33.5.336

14. Chodzko-Zajko WJ, Proctor DN, Fiatarone Singh MA, et al; American College of Sports Medicine. American College of Sports Medicine position stand. Exercise and physical activity for older 
adults. Med Sci Sports Exerc. 2009;41:1510-1530. PubMed ID: 19516148

doi:10.1249/MSS.0b013e3181a0c95c

15. Rikli RE, Jones $\mathrm{CJ}$. The reliability and validity of a 6-minute walk test as a measure of physical endurance in older adults. J Aging Phys Act. 1998;6:363-375. doi:10.1123/japa.6.4.363

16. Perera S, Mody SH, Woodman RC, Studenski SA. Meaningful change and responsiveness in common physical performance measures in older adults. J Am Geriatr Soc. 2006;54:743-749. PubMed ID: 16696738 doi:10.1111/j.1532-5415.2006.00701.x

17. Stewart AL, Mills KM, King AC, Haskell WL, Gillis D, Ritter PL. CHAMPS physical activity questionnaire for older adults: outcomes for interventions. Med Sci Sports Exerc. 2001;33:1126-1141. PubMed ID: 11445760 doi:10.1097/00005768-200107000-00010

18. Colbert LH, Matthews CE, Havighurst TC, Kim K, Schoeller DA.Comparative validity of physical activity measures in older adults. Med Sci Sports Exerc. 2011;43:867-876. PubMed ID: 20881882 doi:10.1249/MSS.0b013e3181fc7162

19. Studenski S, Perera S, Patel K, et al. Gait speed and survival in older adults. JAMA. 2011;305:5058. PubMed ID: 21205966 doi:10.1001/jama.2010.1923

20. Judge JO, Schechtman K, Cress E. The relationship between physical performance measures and independence in instrumental activities of daily living. The FICSIT group. Frailty and injury: Cooperative Studies of Intervention Trials. J Am Geriatr Soc. 1996;44:1332-1341. PubMed ID: 8909349 doi:10.1111/j.1532-5415.1996.tb01404.x

21. Abellan Van Kan G, Rolland Y, Andrieu S, et al. Gait speed at usual pace as a predictor of adverse outcomes in community-dwelling older people an International Academy on Nutrition and Aging (IANA) Task Force. 2010.

22. Lee PG, Ha J, Blaum CS, Gretebeck K, Alexander NB. Patterns of physical activity in sedentary older individuals with type 2 diabetes. Clin Diabetes Endocrinol. 2018;4:2-7. PubMed ID: 29662686 doi:10.1186/s40842-018-0057-4

23. Romero-Arenas S, Martínez-Pascual M, Alcaraz PE. Impact of resistance circuit training on neuromuscular, cardiorespiratory and body composition adaptations in the elderly. Aging Dis. 2013;4:256-263. PubMed ID: 24124631 doi:10.14336/AD.2013.0400256

24. Allet $L$, Armand $S$, de Bie RA, et al. The gait and balance of patients with diabetes can be improved: a randomised controlled trial. Diabetologia. 2010;53:458-466. PubMed ID: 19921145 doi:10.1007/s00125-009-1592-4

25. Tsang T, Orr R, Lam P, Comino EJ, Singh MF. Health benefits of Tai Chi for older patients with type 2 diabetes: the "Move It for Diabetes Study"-a randomized controlled trial. Clin Interv Aging. 2007;2:429-439. PubMed ID: 18044193

26. Straudi S, Martinuzzi C, Pavarelli C, et al. A task-oriented circuit training in multiple sclerosis: a feasibility study. BMC Neurol. 2014;14:124. PubMed ID: 24906545 doi:10.1186/1471-2377-14124

27. English C, Hillier SL. Circuit class therapy for improving mobility after stroke. Cochrane Database Syst Rev. 2010;(7):CD007513.

28. Park S-Y, Lee I-H. Effects on training and detraining on physical function, control of diabetes and anthropometrics in type 2 diabetes; a randomized controlled trial. Physiother Theor Pract. 2015;31:83-88. doi:10.3109/09593985.2014.958265 
29. Dunstan DW, Daly RM, Owen N, et al. Home-based resistance training is not sufficient to maintain improved glycemic control following supervised training in older individuals with type 2 diabetes. Diabetes Care. 2005;28:3-9. PubMed ID: 15616225 doi:10.2337/diacare.28.1.3

30. Dunstan DW, Daly RM, Owen N, et al. High-intensity resistance training improves glycemic control in older patients with type 2 diabetes. Diabetes Care. 2002;25:1729-1736. PubMed ID: 12351469 doi:10.2337/diacare.25.10.1729

31. Cummings SR, Studenski S, Ferrucci L. A diagnosis of dismobility-giving mobility clinical visibility: a mobility working group recommendation. JAMA. 2014;311:2061-2062. PubMed ID: 24763978 doi:10.1001/jama.2014.3033

32. Alexander NB, Galecki AT, Grenier ML, et al. Task-specific resistance training to improve the ability of activities of daily living-impaired older adults to rise from a bed and from a chair. J Am Geriatr Soc. 2001;49:1418-1427. PubMed ID: 11890578 doi:10.1046/j.15325415.2001.4911232.x 